Article

\title{
Game Theory-Based Framework for Analyzing the Collaborative Dynamic of Tacit Knowledge Sharing and the Choice of Procurement and Contract Types in Mega Construction Projects
}

\author{
Jong Han Yoon and Pardis Pishdad-Bozorgi *
}

Citation: Yoon, J.H.; Pishdad-Bozorgi, P. Game Theory-Based Framework for Analyzing the Collaborative Dynamic of Tacit Knowledge Sharing and the Choice of Procurement and Contract Types in Mega Construction Projects. Buildings 2022, 12, 305.

https://doi.org/10.3390/

buildings12030305

Academic Editors:

Agnieszka Leśniak and

Krzysztof Zima

Received: 4 January 2022

Accepted: 2 March 2022

Published: 4 March 2022

Publisher's Note: MDPI stays neutral with regard to jurisdictional claims in published maps and institutional affiliations.

Copyright: (C) 2022 by the authors. Licensee MDPI, Basel, Switzerland. This article is an open access article distributed under the terms and conditions of the Creative Commons Attribution (CC BY) license (https:// creativecommons.org/licenses/by/ $4.0 /)$.

\author{
School of Building Construction, College of Design, Georgia Institute of Technology, Atlanta, GA 30332, USA; \\ jyoon337@gatech.edu \\ * Correspondence: pardis.pishdad@gatech.edu
}

\begin{abstract}
In construction projects, owners' and contractors' decisions as to whether or not share their tacit knowledge transparently with each other determines the choice of project delivery and contracting methods and their collaborative behaviors in the projects. The dynamic of collaboration is a complex one and is often influenced by the other player's intent to collaborate. This paper proposes a quantitative framework using game theory to analyze the collaborative dynamic interplay in construction projects. The framework demonstrates that when an owner's and a contractor's knowledge leveragability $(L)$ is very high and synergy $(S)$ is enhanced as a result of knowledge sharing in complex construction projects, the Nash equilibrium state lies beneath the Pareto frontier This means that sharing tacit knowledge transparently about budgets by choosing the best value procurement with GMP or IPD contracts can promote collaboration and provide better payoffs to both stakeholders than not sharing the knowledge by choosing the Design-Bid-Build method using a low-bid procurement in conjunction with a fixed-price contract. This research contributes to the body of knowledge by proposing a theoretical framework that enables both owners and contractors to understand the economics of collaboration in the context of complex projects.
\end{abstract}

Keywords: game theory; Nash equilibrium; optimal decision; Pareto optimality; tacit knowledge; knowledge sharing in construction projects

\section{Introduction}

Tacit knowledge means individuals' comprehension, capabilities, skills, and experiences on a given topic or situation [1]. This knowledge is embodied in the form of thoughts, points of view, evaluations, and advice, which may be leveraged for individual and organizational benefits. In construction projects, tacit knowledge-sharing among project stakeholders is critical because most construction work is knowledge-intensive, and knowledge on the project is experienced-based and tacit $[2,3]$. Consequently, many studies have explored the nature of tacit knowledge $[1,4,5]$ and tacit knowledge-sharing $[2,3,6-9]$ in the construction industry. However, most of these studies have focused on tacit knowledge management and sharing in project teams involving individuals, such as architects, engineers, and contractors. To date, there are no studies that have devoted attention to tacit knowledge-sharing between project owners and contractors.

Considering that owners are responsible for securing and managing funds and paying team members in construction projects [10], information related to financing can affect owners' decision making or behaviors in the context of construction projects. From this perspective, owners possess tacit knowledge associated with project budget; they know the maximum budget that can be financed for construction projects. They decide whether to share this knowledge or withhold it from contractors depending on the selected procurement and contract methods. According to Hwang [7], contractors mainly have tacit 
knowledge of pricing and operational strategies for construction engineering and management. In construction projects, the contractors can decide whether to share this tacit knowledge or withhold it from owners depending on the selected procurement and contract methods. Accordingly sharing tacit knowledge between owners and contractors is closely associated with the owners' decisions on procurement and contract types and the contractors' decisions on being collaborative and committed to knowledge sharing in the projects.

The current dilemma is that owners may not fully understand how their decision on procurement and contract types could trigger contractors' collaborative versus opportunistic behavior. Moreover, contractors may not fully understand the economical payoffs of their knowledge sharing and collaborative behavior. This lack of understanding and uncertainties may lead to decisions that result in owners incurring higher costs and facing more change orders, or contractors earning less profit as well as gaining a damaged reputation because of multiple disputes and claims. Thus, an undesirable lose-lose situation as opposed to win-win results.

Nevertheless, the definitions of owners' and contractors' tacit knowledge, the impact of sharing the knowledge on both stakeholders, and how the decision on whether to share the knowledge can be made have not yet been studied. To overcome the knowledge gap, this study aims to (1) define tacit knowledge of owners and contractors, (2) analyze the economic payoffs of tacit knowledge sharing for both owners and contractors, (3) propose a theoretical framework that would help owners identify the optimal procurement and contract methods for complex projects where enhanced collaboration is needed. Through the framework the owners would understand how their choice of procurement and contract would incentivize and trigger contractors' collaborative behavior. The framework also enables contractors to determine the economic payoffs from their collaborative actions in a project-specific context.

The framework involves defining and quantifying the value of tacit knowledge of owners and contractors as well as analyzing the estimated payoffs based on game theory, along with an analysis of the Nash equilibrium and Pareto optimality. In addition, by simulating the framework with hypothetical scenarios of a mega construction project, this study illustrates and validates the effectiveness of the framework in identifying the most optimal procurement and contract type for triggering collaborative behavior and in determining the circumstances when collaboration maximized individual payoffs for both owners and contractors, leading to a win-win outcome and a successful project.

This paper is structured into several sections. The literature review is conducted in order to identify the research gaps of previous studies on tacit knowledge sharing in construction projects. This is followed by descriptions of the game-theoretic method to define owners' and contractors' tacit knowledge and measure the payoffs of sharing tacit knowledge. Respectively, the framework is developed and validated by a series of simulations using hypothetical scenarios of a mega contraction project. Finally, the paper discusses the simulation results and clarifies the study's contributions to both theoretical knowledge and practical applications in the construction industry.

\section{Literature Review}

\subsection{Nature of Tacit Knowledge in the Construction Industry}

A study from Pathirage et al. [5] indicates that tacit knowledge in the construction industry involves the skills, experiences, and talents of construction workers. In another study [1], the authors specified the key aspects of tacit knowledge in the construction industry by conducting a case study of a company and interviews with directors, managers, and operational level personnel. According to the interviews, tacit knowledge in the construction industry involves estimating and tendering skills, understanding the construction process, interacting with project owners and team members in the construction supply chain, and comprehending the tender markets. Shan and Li [11] also explain that tacit knowledge in the construction supply chain includes engineering experience, accumu- 
lated management experience, and technical skills. Egbu and Robinson [12] revealed that tacit knowledge in construction can range from the plastering ability of workers to the interactions among stakeholders in the construction supply chain.

Most of the knowledge in the construction industry is tacit rather than explicit, and sharing tacit knowledge is imperative for enhanced project performance [13]. Tacit knowledge is critical to organizational performance due to the labor-intensive and knowledgeintensive nature of the construction industry, involving a wide range of professionals working as an interdisciplinary team to successfully deliver the construction projects [14]. In addition to organizational performance, it is also critical to construction performance associated with construction innovation, process improvement, and quality improvement $[15,16]$. However, Saini et al. [16] argued that communicating tacit knowledge is challenging in the construction industry because tacit knowledge exists in the mind of construction stakeholders and decisions on whether to share tacit knowledge or not depends on stakeholders and their individual perceptions of the associated benefits. Kivrak and Arslan [17] also pointed out that tacit knowledge resides in people's heads, and it is difficult to transfer.

\subsection{Tacit Knowledge Sharing in the Construction Industry}

Many recent studies highlighted the impact of tacit knowledge sharing on construction project performance and the difficulties of capturing and transferring tacit knowledge across the construction supply chain [15-18]. Subsequently, several studies have examined the challenges and opportunities of efficiently sharing tacit knowledge and identified the critical factors influencing tacit knowledge sharing in construction [2,6-8].

Nesan [6] emphasized that the temporary nature of construction projects and the short-term relationships among project team members hindered the exchange of tacit knowledge. The study also revealed that construction knowledge, which was often tacit, disappeared when the project was completed. To resolve the foregoing, the study identified five major critical factors influencing knowledge sharing behavior (trust, creativity, motivation, ability, and learning) of personnel in construction. The study subsequently proposed work practices based on the identified factors that can influence the behaviors of personnel in transferring tacit knowledge in the construction organization. Zhang and He [2] also investigated crucial factors affecting tacit knowledge-sharing within integrated teams of construction projects. They identified the five critical factors to be swift-trust, informationbased trust, identification-based trust, personal benefits, and lack of self-efficacy. The study argued that the findings provide important implications for promoting tacit knowledge sharing among integrated project teams. Hwang [7] argued that sharing tacit knowledge in the construction industry requires active interaction between knowledge-holders and knowledge-seekers. By surveying construction industry practitioners, the study investigated a few considerable problems in terms of the maturity of organizational ecology for exchanging tacit knowledge at the workplace in the industry. The survey results indicated that the construction industry lacked company-wide internal interaction among employees. They recommended that the inter-organizational interaction through the communities of practice should be made more active to raise the overall effectiveness in sharing tacit knowledge. Chen and Mohamed [8] also emphasized the importance of human interactions for facilitating tacit knowledge sharing in the construction industry. The survey results of contractors empirically proved that knowledge was essentially personal and inseparable from the knower. The research demonstrated that people-centric tacit knowledge management was required and should be combined with IT systems to make the strategic decisions in tacit knowledge sharing explicit in form.

The aforementioned studies have investigated the factors influencing tacit knowledge sharing. However, they were limited to the knowledge of construction workers and professionals whose tacit knowledge differs from that of stakeholders in the construction supply chain. For example, the project owners may have knowledge related to project financing, and the suppliers may be knowledgeable of material supply logistics; despite the difference, the knowledge of both groups can considerably affect construction project 
performance. Furthermore, the stakeholders may be uninterested in sharing their tacit knowledge for several reasons (e.g., competitiveness and interest in profits). However, none of the reviewed studies have offered solutions to problems which deter tacit knowledge sharing in the construction industry.

Other studies have investigated various means of facilitating tacit knowledge sharing in the construction industry [3] and the impact of such sharing [9,19]. Woo et al. [3] proposed creating and testing a web-based knowledge map to enable tacit knowledge sharing among construction professionals. The proposed knowledge map enables construction professionals to search for experts with relevant knowledge and connect with them in real time using instant messaging, e-mail, telephone, or internet conferencing. However, because knowledge sharing requires trust among stakeholders and involves consideration of the personal benefits sought by the knowledge givers, this may not necessarily ensure that the professionals indeed share their tacit knowledge [2]. Jung et al. [19] investigated the impact of trust-based collaboration among the project stakeholders in Design-Build (DB) and Integrated Project Delivery (IPD) settings where Target Value Design (TVD) was applied. The study revealed how the TVD in an IPD contract enables each stakeholder to collaborate on initial design alignment, using game theory. Zhang et al. [9] empirically examined the impact of tacit knowledge sharing within an integrated project delivery team through a case study. The study demonstrated that tacit knowledge sharing among project team members improved the flexibility and increased the overall collaboration and synergy of the team. It aided team members to proactively manage the project at an early stage, identify critical factors for project success, and plan reaction measures for potential dynamics. However, the investigation was limited to knowledge sharing among the contractors during the construction phase, whereas the other stakeholders shared their tacit knowledge at various stages. The owners and contractors can share their tacit knowledge at the pre-construction phase or bidding phase, and the contractors can transfer their tacit knowledge to facility maintenance teams and project owners at the handover phase.

The existing studies on tacit knowledge sharing have majorly focused on knowledge sharing among construction workers and professionals in the construction phase. However, various stakeholders exist in the construction supply chain, and each may have tacit knowledge regarding some aspects of the project lifecycle. In particular, tacit knowledge sharing between owners and contractors throughout the procurement and construction phases could substantially affect project quality and cost. Hence, it is necessary to define owners' and contractors' tacit knowledge and develop a framework comparing the payoffs in sharing or not sharing tacit knowledge in construction projects. This paper bridges this research gap by defining owners' and contractors' tacit knowledge, proposing a framework to compare the payoffs of tacit knowledge sharing, and demonstrating the framework with specific scenarios of tacit knowledge sharing between owners and contractors.

\section{Research Methodology}

\subsection{Dimensions for Quantifying Value of Tacit Knowledge}

As an initial step to develop the framework, this study defines owners' and contractors' tacit knowledge in a construction project. Next, the value of their tacit knowledge is defined as a measurable form based on the dimensions proposed by Loebecke et al. [20] (Table 1).

Loebecke et al. [20] introduced a game-theoretic framework for analyzing interorganizational knowledge sharing. In their theoretic framework, they provided five dimensions for quantifying the value of knowledge when sharing knowledge under the context of co-opetition. Co-opetition is a neologism to describe the state of organization where cooperation and competition simultaneously exist among stakeholders. Under co-opetition, knowledge shared for cooperation may also be used for competition. Owners and contractors in a construction project are in a co-opetition situation in which they cooperate with each other to achieve a successful project while they seek to increase their individual gains and profits. For example, owners want quality projects at lower costs, while contractors pursue a higher price and least work for the project to increase their individual 
profits. Accordingly, the dimensions proposed by Loebecke et al. [20], including basic value, value-added associated with monopolistic knowledge, synergy, leveragability, and negative-reverse impact, can be applied to this study (Table 1). These dimensions enable the stakeholders under the co-opetition context to estimate the value of tacit knowledge sharing.

Table 1. Five dimensions for quantifying value of knowledge in co-opetition (Loebecke et al., 1999).

\begin{tabular}{cc}
\hline Dimensions & Definitions \\
\hline Basic value $\left(r_{i}\right)$ & $\begin{array}{c}\text { Fundamental, inherent value of knowledge } \\
\text { Value-added }\left(v a_{i}\right)\end{array}$ \\
Synergy $(S)$ & $\begin{array}{c}\text { Value-added generated by monopolistic knowledge } \\
\text { Additional value resulting from interdependent } \\
\text { knowledge sharing among stakeholders }\end{array}$ \\
Leveragability $\left(L_{i}\right)$ & Value generated when knowledge-receiving party \\
exploits shared knowledge
\end{tabular}

\subsection{Game-Theoretic Approaches to Tacit Knowledge-Sharing in Construction Projects}

Based on these five dimensions, this study develops a framework to quantify the value of owners' and contractors' tacit knowledge when transferring or not transferring the knowledge to each other. The framework involves defining the value of the tacit knowledge and computing a payoff matrix that indicates the payoffs of each stakeholder's decision on whether or not to share their tacit knowledge. During the knowledge sharing between owners and contractors, one stakeholder's decision payoff is affected by another stakeholder's decision. Game theory enables us to quantitatively compare the payoffs of each decision in situations where two or more stakeholders' actions will influence the actions of the other [21]. Consequently, game theory is applied to understand and analyze the payoffs resulting from each decision of the two stakeholders. The payoffs of each decision in the matrix are analyzed based on the two game-theoretic approaches: (1) Nash equilibrium and (2) Pareto optimality. This approach is inspired by Raweewan and Ferrell, Jr [22].

\subsubsection{Nash Equilibrium}

The Nash equilibrium is a strategic profile in which each player's strategy (or decision) is an optimal response to the other players' strategies [23]. In the Nash equilibrium state, no player would gain additional benefits by deviating when the opposing player does not deviate [24]. In the tacit knowledge-sharing game between owners and contractors, based on the definition of the Nash equilibrium provided by Hitzig et al. [24], this study constructs the following definition of the Nash equilibrium (Definition 1) to determine the optimal decision on whether or not to transfer tacit knowledge, given the other stakeholder's decision in construction projects:

Definition 1. The tacit knowledge-sharing game is a two-player game with finite strategies. One of the players is denoted as player $i$ and the opposing player as player $-i$. For example, when $i$ represents an owner (o) of a construction project, -i represents a contractor $(c)$ in the construction project. Strategies available to player $i$ are denoted $a s s_{i} . S_{i} i$ the set of all possible strategies for player $i$. The strategies consist of transfer tacit knowledge $(T)$ and do not transfer tacit knowledge $(D N T), S_{i}=\{T, D N T\}$. If $s_{i}$ is a strategy available to player $i, s_{i}{ }_{i}$ will be a different strategy available to player $i$. Given this, each strategy profile provided by two players can be referred to as $\left(s_{i}, s_{-i}\right)$, while $u_{i}\left(s_{i}, s_{-i}\right)$ represents payoffs of player $i$ when the strategy profile is $\left(s_{i}, s_{-i}\right)$. Subsequently, the strategy profile $\left(s_{i}, s_{-i}\right)$ is a Nash equilibrium if it follows the below Function (1):

$$
\text { For } \forall i \text { and } \forall s_{i}, u_{i}\left(s_{i}, s_{-i}\right) \geq u_{i}\left(s^{\prime}{ }_{i}, s_{-i}\right)
$$


where $\forall=$ a logical symbol meaning "for all"; $s_{i}=$ a strategy available to player $i ; s^{\prime}{ }_{i}=$ a different strategy available to player $i$; and $s_{-i}=a$ strategy available to player $-i$.

\subsubsection{Pareto Optimality}

Even though the Nash equilibrium provides stakeholders with optimal strategies (or decisions) for a non-zero-sum game [22], it does not mean that the stakeholders always obtain the maximized payoffs. This situation, in which the stakeholders are not able to obtain maximized payoffs in Nash equilibrium state, is called the Prisoners' dilemma. To check if the stakeholders are in the Prisoners' dilemma or not, they can analyze their state based on the Pareto optimality (or Pareto efficiency). The Pareto optimality is an economic state in which no player can be made better off without making other player worse off [25]. In other words, the state, which is not Pareto-optimal, enables both players to increase their payoffs simultaneously by deviating from the non-Pareto-optimal state to the Pareto-optimal state. Accordingly, the Pareto optimality analysis enables us to confirm whether or not a change of decisions from the game players can increase both players payoffs. If the state is Pareto-optimal, it should be examined that the state provides the maximized payoffs equally shared with the players. However, when the game is using a Likert scale, the state may not be identified because the scales are fragmented (e.g., 1, 2, 3, 4 , and 5) and the value of the equally shared payoffs in the state may locate between the fragmented scales (e.g., 2.4, 3.5, and 4.7). In this case, a player, who has better payoffs, can propose an offer to share the added payoffs with an opposing player so that the players can decide to deviate from the non-Pareto-optimal state to the Pareto-optimal state.

In the tacit knowledge-sharing game between owners and contractors, based on the aforementioned concept of the Pareto optimality, this study uses the following definition of Pareto optimality (Definition 2) to determine whether the stakeholders obtain the maximized payoffs:

Definition 2. When following the conditions associated with $i$ and si in Definition 1, for $\forall i$ and $\forall s_{i}$, the decision-making strategy profile $\left(s_{i}, s_{-i}\right)$ is Pareto-optimal when $u_{i}\left(s_{i}, s_{-i}\right)$ is not able to become better off without making $u_{-i}\left(s_{i}, s_{-i}\right)$ worse off.

Although we have provided the theoretical definitions of Nash equilibrium and Pareto optimality in the context of the tacit knowledge sharing game in construction projects, these definitions have their limitations. Owners' and contractors' decisions related to the sharing of tacit knowledge and the payoffs will be limited to the predetermined parameters for measuring the values of different strategies derived from the definitions. Thus, in a real scenario involving the sharing of tacit knowledge, owners and contractors may adjust these parameters based on their project characteristics. Nevertheless, the theoretical definitions can help owners and contractors to analyze the payoffs resulting from sharing or not sharing their tacit knowledge. Even though a few of the parameters used for determining the decision strategies and the states of Nash equilibrium and Pareto optimality should be adjusted depending on the unique characteristics of a project, we expect that the construction management and engineering domain can benefit from the proposed approach by leveraging the proposed definitions customized to tacit knowledge sharing between owners and contractors in construction projects.

\section{Tacit Knowledge of Owners and Contractors}

\subsection{Owners' Tacit Knowledge}

Because of the complexity and diversity of tacit knowledge, there are extensive disagreements regarding what should be counted as tacit knowledge and what the general characterization of the concept should be [4]. Especially as complexity and diversity are aggravated in defining owners' tacit knowledge, since they have never been investigated and studied. However, many studies from various domains have agreed that tacit knowl- 
edge involves contextual information that affects decision making or behaviors within the context $[4,7,26,27]$. Considering that owners are responsible for securing and managing funds and paying team members in construction projects [10], information related to the financing can affects owners' decision making or behaviors in the context of construction projects. From this perspective, this study assumes that owners possess tacit knowledge associated with project budgets; they know the maximum cost or financial incentive that can be financed for construction projects. They decide whether to share this knowledge or withhold it from contractors depending on the selected procurement and contract methods. For example, in low-bid procurements in conjunction with lump-sum contracts, the owners choose not to provide contractors with this tacit knowledge. In contrast, in best value procurements with guaranteed maximum price (GMP) or integrated project delivery (IPD) contracts, owners may opt to disclose their available project budget with contractors, share project risks, and use financial incentives to reward quality performance and innovation. Indeed, the instance in which owners may not have any tacit knowledge associated with the project budget is excluded from the scope of this study because rational decisions related to the procurement and contract methods cannot be made in such an instance.

Each decision has its advantages and disadvantages. When owners choose not to share their tacit knowledge regarding budget by selecting contractors through low-bid procurement and executing a lump-sum contract in DBB projects, owners are at risk of receiving a low-quality construction project and receiving change order requests as opportunistic contractors use change orders as a mean of increasing their individual profits.

To achieve quality construction, owners can select contractors through best value procurement and also share their tacit knowledge on budget by establishing a GMP in CM@Risk projects or Estimated Maximum Price (EMP) in IPD contract-based projects and sharing financial risks with contractors through incentives and disincentives. However, owners may not fully trust that the contractors will actually become engaged in the best value procurement with GMP or IPD contracts with full transparency and commitment.

\subsection{Contractors' Tacit Knowledge}

According to Hwang [7], contractors mainly have tacit knowledge of pricing and operational strategies for construction engineering and management and benefit by sharing the knowledge. In construction projects, the contractors can decide whether to share this knowledge or withhold it from owners depending on the selected procurement and contract methods. For example, they are able to identify design or engineering errors or omission in the bidding phase of DBB projects, understand which construction engineering methods should be applied for the expected project quality, and estimate prices for the projects. This study defines this knowledge as tacit knowledge for contractors. Contractors can share this knowledge with owners by informing them of design or engineering errors and omissions when bidding on a DBB project. However, opportunistic contractors may choose not to bring to the owners' attention design or engineering errors they discover at the time of bidding in DBB projects with the motivation to increase their individual profits through change orders after they are awarded the project. In case of the project using best value procurement with GMP or IPD contracts, contractors can share their tacit knowledge with owners by engaging in the projects with full transparency and commitment to sharing knowledge of pricing and operational strategies for construction engineering and management.

When it comes to making decisions on tacit knowledge sharing, contractors are faced with two options: (1) to share their knowledge in order to build good relationships with owners, develop a reputation for high quality work, and/or to gain additional financial incentives per contract; (2) to pursue opportunistic business practices by not sharing their tacit knowledge in order to gain additional profits. However, contractors find it challenging to determine which decision overall would make them better off. Table 2 summarizes the definitions of owners' and contractors' tacit knowledge and their knowledge sharing in construction projects. 
Table 2. Owners' and contractors' tacit knowledge sharing scenarios in construction projects.

\begin{tabular}{cll}
\hline Tacit knowledge & $\begin{array}{l}\text { Knowledge associated with financial capability } \\
\text { for the project }\end{array}$ & $\begin{array}{l}\text { Knowledge associated with construction } \\
\text { operational strategy and pricing }\end{array}$ \\
\hline Transfer knowledge & $\begin{array}{l}\text { Best value procurement with GMP or IPD } \\
\text { contracts (risk-sharing and incentives) }\end{array}$ & $\begin{array}{l}\text { Sharing knowledge on design and engineering } \\
\text { errors and omission in the bidding phase of } \\
\text { the projects in the DBB delivery method } \\
\text { Engaging in best value procurement with } \\
\text { Do not transfer knowledge }\end{array}$ \\
\hline $\begin{array}{l}\text { GMP or IPD contracts with full transparency } \\
\text { contract (lowest price, no risk sharing, no } \\
\text { incentives) in the project using the DBB } \\
\text { delivery method }\end{array}$ & $\begin{array}{l}\text { Concealing design and engineering errors in the } \\
\text { bidding phase of the projects in the DBB delivery } \\
\text { method and making change orders in the } \\
\text { construction phase }\end{array}$ \\
\hline
\end{tabular}

\subsection{Quantifying Value of Owners' and Contractors' Tacit Knowledge}

This study applies the five dimensions proposed by Loebecke et al. [20] to determine the value of tacit knowledge in construction projects (Table 3), namely: (1) basic value $\left(r_{i}\right)$, (2) value-added $\left(v a_{i}\right),(3)$ synergy $(S),(4)$ leveragability $\left(L_{i}\right)$, and (5) negative-reverse impact $\left(n r i_{i}\right)$.

Table 3. Owners' and contractors' tacit knowledge value in construction projects.

\begin{tabular}{lll}
\hline & \multicolumn{1}{c}{ Owners } & \multicolumn{1}{c}{ Contractors } \\
\hline Basic value $\left(r_{i}\right)$ & $\begin{array}{l}r_{O} \text { : Fundamental, inherent value of } \\
\text { knowledge associated with } \\
\text { financial capability }\end{array}$ & $\begin{array}{l}r_{C} \text { : Fundamental, inherent } \\
\text { value of knowledge associated } \\
\text { with construction operational } \\
\text { strategy and pricing }\end{array}$ \\
\hline Value-added $\left(v a_{i}\right)$ & $\begin{array}{l}v a_{O} \text { : Lowest price resulting from low bid } \\
\text { procurement and risk avoidance through } \\
\text { a lump-sum contract }\end{array}$ & $\begin{array}{l}v a_{C} \text { : Individual profits } \\
\text { resulting from change orders }\end{array}$ \\
\hline Synergy $(S)$ & $\begin{array}{l}S: \text { Additional value beyond the tangible benefits from the stakeholders' } \\
\text { individual knowledge (e.g., high level of collaboration, fewer disputes and } \\
\text { claims, long-term relationships, reputation in the industry, etc.) }\end{array}$ \\
\hline $\begin{array}{l}\text { Leveragability }\left(L_{i}\right) \\
\text { Negative-reverse }\end{array}$ & $\begin{array}{l}L_{O}: \text { Fewer change orders, adequate price, } \\
\text { and quality works }\end{array}$ & $L_{C}$ : Incentives or risk sharing \\
\hline \multicolumn{1}{c}{$\left.n i_{i}=v a_{i}\right)$} &
\end{tabular}

The basic value $(r)$ is the basic, inherent value placed on the information [22]. Accordingly, with respect to owners' tacit knowledge, the basic value $\left(r_{O}\right)$ is the fundamental, inherent value of the knowledge associated with owners' financial capability. Value-added (va) means additional value generated when the information is not shared with other stakeholders [22]. Based on this definition, the value-added dimension of owners $\left(v a_{O}\right)$ is the value generated when owners do not transfer their tacit knowledge. Therefore, it refers to the profits resulting from the lowest price and risk avoidance through low-bid procurement in conjunction with a lump sum contract. The leveragability $(L)$ refers to the value increment of the knowledge-receiving party when the party exploits the shared knowledge on its own beyond the cooperation [20]. Accordingly, the leveragability of owners $\left(L_{O}\right)$ is the value that owners can exploit when contractors transfer their tacit knowledge to them. It can involve fewer change orders, a reasonable bidding price, and high-quality works from the contractors. 
These variable determination processes based on the theoretical background from literature are identically applied to contractors' tacit knowledge. As for contractors' tacit knowledge, the basic value $\left(r_{C}\right)$ is the fundamental, inherent value of the knowledge associated with contractors' construction operational and pricing strategy. The value-added $\left(v a_{C}\right)$ dimension is the value generated when contractors do not transfer the knowledge related to the operational strategy and pricing. The value can be denoted as individual profits resulting from concealing design and engineering errors in the bidding phase of projects in the DBB delivery method and making change orders in the construction phase. The leveragability $\left(L_{C}\right)$ refers to the potential profits that contractors can make when owners transfer their tacit knowledge. It involves risk sharing through contingency or incentives based on their performance.

Both owners and contractors reach synergy $(S)$ when they share their tacit knowledge with each other. This synergetic value means additional value that co-operation yields from interdependent knowledge sharing beyond the sum of the stakeholders' individual knowledge [20]. For example, in our study, synergy $(S)$ dimension refers to the potential positive impact on both stakeholders, such as increased collaboration and reduced number of disputes and claims. Furthermore, other non-financial benefits, such as long-term relationships between stakeholders and reputation in the industry, can be considered as synergy dimensions. The negative-reverse impact $\left(n r i_{i}\right)$ is the negative impact on the knowledge-sender, when shared knowledge is used by the knowledge receiver against the knowledge sender [20]. In this tacit knowledge-sharing game, we assume that the value of the negative-reverse impact $\left(n r i_{i}\right)$ is equivalent to the value of the value-added $\left(v a_{i}\right)$ dimension because the knowledge-sender is negatively affected by losing the value-added dimension when the knowledge-receiver exploits the shared knowledge.

Applying the above dimensions in Table 3, this study constructs the payoffs matrix of the tacit knowledge transferring game for construction projects. The matrix indicates payoffs for each stakeholder when the stakeholder transfers or does not transfer their knowledge based on the other stakeholders' choice to transfer or not transfer their knowledge. For example, the matrix consists of four sets of decision profiles from the two stakeholders, and the decision profiles are illustrated as (owner's decision, contractor's decision). Transferring tacit knowledge is denoted as (T) and not transferring tacit knowledge as (DNT). Subsequently, the set of decision profiles is indicated as (T, T), (T, DNT), (DNT, T), and (DNT, DNT). In the context of $(\mathrm{T}, \mathrm{T})$, the owner can estimate their payoff with the function below:

$$
\text { Owner's payoff in the context of }(\mathrm{T}, \mathrm{T})=r_{O}+r_{C}+S+L_{O}-n r i_{O}
$$

Since the contractor transfers their knowledge, the owner has $r_{C}$ and $L_{O}$ while the owner is affected by $n i_{O}$ because they transfer their knowledge. In addition to these elements, the owner has the fundamental value of the knowledge $\left(r_{O}\right)$ and $S$ led by the synergistic knowledge transfer. In the same way, the contractor's payoff can be computed with the below function:

$$
\text { Contractor's payoff in the context of }(\mathrm{T}, \mathrm{T})=r_{O}+r_{C}+S+L_{C}-n r i_{C}
$$

In the context of (T, DNT), the owner's payoff does not involve $S$ or $L$ because the contractor does not transfer its knowledge. However, the contractor's payoff contains $r$ from the owner $\left(r_{O}\right)$ and $L$ generated by exploiting the owner's transferred knowledge $\left(L_{C}\right)$. Furthermore, it includes $v a_{C}$ because the contractor has monopolistic knowledge by not sharing knowledge with the owner. This approach identically applies to the context of (DNT, T). Accordingly, the owner's and contractor's payoffs in the context of (T, DNT) and (DNT, T) are computed with these functions:

$$
\text { Owner's payoff in the context of }(\mathrm{T}, \mathrm{DNT})=r_{O}-n r i_{O}
$$




$$
\begin{gathered}
\text { Contractor's payoff in the context of }(\mathrm{T}, \mathrm{DNT})=r_{O}+r_{C}+v a_{C}+L_{C} \\
\text { Owner's payoff in the context of }(\mathrm{DNT}, \mathrm{T})=r_{O}+r_{C}+v a_{O}+L_{O} \\
\text { Contractor's payoff in the context of }(\mathrm{DNT}, \mathrm{T})=r_{C}-n r i_{C}
\end{gathered}
$$

Finally, in the context of (DNT, DNT), neither stakeholder has $L$ or $S$. They only have $r$ of their own knowledge and $v a$ resulting from not sharing their knowledge. Consequently, the owner's and contractor's payoffs in the context of (DNT, DNT) are computed with these functions:

$$
\begin{aligned}
& \text { Owner's payoff in the context of }(\mathrm{DNT}, \mathrm{DNT})=r_{O}+v a_{O} \\
& \text { Contractor's payoff in the context of (DNT, DNT) }=r_{C}+v a_{C}
\end{aligned}
$$

All the functions for each payoff are presented in the payoff matrix (Table 4). In Table 5, the procurement and contract types based on the decisions on sharing tacit knowledge of owners are allocated in the matrix. In addition, Table 5 shows the different situations showing the degree of contractors' collaborations in sharing their tacit knowledge.

\begin{tabular}{|c|c|c|c|}
\hline & & \multicolumn{2}{|c|}{ Contractors } \\
\hline & & $\mathbf{T}$ & DNT \\
\hline & $\mathbf{T}$ & $\begin{array}{l}\text { Best Value Procurement with GMP or } \\
\text { IPD Contracts } \\
\text { Owners: } \\
\text { - } \quad \text { Risk-sharing and incentives } \\
\text { Contractors: } \\
\text { - Collaborative mindset and } \\
\quad \text { behavior, full transparency }\end{array}$ & $\begin{array}{l}\text { Best Value Procurement with GMP or } \\
\text { IPD Contracts } \\
\text { Owners: } \\
\text { - Risk-sharing and incentives } \\
\text { Contractors: } \\
\text { - Opportunistic mindset and } \\
\text { behavior }\end{array}$ \\
\hline Owners & DNT & $\begin{array}{l}\text { Low bid procurement with lump-sum } \\
\text { contract } \\
\text { Owners: } \\
\text { - No risk sharing, no incentives } \\
\text { Contractors: } \\
\text { - Sharing knowledge on design } \\
\text { and engineering errors and } \\
\text { omission in bidding phase of } \\
\text { the project using the DBB } \\
\text { delivery method }\end{array}$ & $\begin{array}{l}\text { Low bid procurement with lump-sum } \\
\text { contract } \\
\text { Owners: } \\
\text { - No risk sharing, no incentives } \\
\text { Contractors: } \\
\text { - Concealing design and } \\
\text { engineering errors in the } \\
\text { bidding phase of the project } \\
\text { using the DBB delivery method } \\
\text { and making change orders in } \\
\text { the construction phase }\end{array}$ \\
\hline
\end{tabular}

Table 4. Payoff matrix of tacit knowledge-transferring game in construction projects.

\begin{tabular}{cccc}
\hline \multirow{6}{*}{ Owners } & \multicolumn{2}{c}{ Contractors } \\
\cline { 3 - 4 } & Transfer Tacit & $\left(r_{O}+r_{C}+S+L_{O}-n r i_{O}\right)$, & $\begin{array}{c}\text { Do Not Transfer Tacit } \\
\text { Knowledge (DNT) }\end{array}$ \\
\hline \multirow{4}{*}{ Knowledge (T) } & $\left(r_{O}+r_{C}+S+L_{C}-n r i_{C}\right)$ & $\left(r_{O}-n r i_{O}\right)$, \\
& Do Not Transfer Tacit & $\left(r_{O}+r_{C}+v a_{O}+L_{O}\right)$, & $\left(r_{C}+v a_{C}+L_{C}\right)$ \\
& Knowledge (DNT) & $\left(r_{C}-n r i_{C}\right)$ & $\left(r_{O}+v a_{O}\right)$, \\
& & & $\left(r_{C}+v a_{C}\right)$ \\
\hline
\end{tabular}

Table 5. An Owner's and contractor's tacit knowledge sharing and collaboration scenarios in the context of different procurement and contract types. 


\section{Game-Theoretical Analysis of Potential Scenarios in Construction Projects}

In this section, the tacit knowledge dimensions in the above payoff matrix are encoded with numerical values and the matrix is analyzed with the two game-theoretical approaches using the Nash equilibrium and Pareto optimality. The Nash equilibrium determines the most risk-safe and optimal decision pair for both stakeholders. Both stakeholders assess their decision payoffs while considering different scenarios resulting from the other stakeholder's decision and choose the most risk-safe option. The Nash equilibrium state may not provide maximized payoffs to the stakeholders. In some circumstances, it provides better payoffs when both stakeholders trust each other and deviate from the Nash equilibrium. To capture these circumstances, we use the Pareto optimality approach. Pareto optimality shows whether a decision generates maximized payoffs. If the Pareto optimal decision generates better payoffs for both stakeholders than the decisions in the Nash equilibrium, the stakeholders should trust each other and deviate from the decisions to the Pareto optimality. As a result, by combining these two approaches, the stakeholders are able to comprehend which decision is optimal in obtaining the best payoffs of the knowledge transfer.

This paper provides an example to illustrate the proposed framework's benefits and the ways in which the methodology can be used. The hypothetical project scenarios used in the example encompass project complexity, because the dimension variables involving $v a_{i}$, $L_{i}$, and $S$ are affected by the perceived project risk and difficulty as by-products of project complexity. Based on the scenarios, the values of the dimensions in the framework are numerically estimated using a 5-point Likert scale. For this scale, 1 represents "very low" and 5 represents "very high." Consequently, the payoff matrix is computed and analyzed with game-theoretical approaches. Given the matrix and analysis, the optimal decision on whether to share tacit knowledge is identified in each scenario.

\subsection{Example: Large and Complex Projects with High Risk}

The hypothetical project scenarios are developed based on the characteristics of large and complex projects, also referred to as construction megaprojects. The primary characteristics involve high cost, high complexity, and uncertainty that are revealed by the study of Fiori and Kovaka [28]. This type of projects is emerging nowadays because the complexity of project scopes and environments are increasing [28-30]. Construction projects for highrise commercial buildings, airports, hospitals, and industrial projects can be examples of this project type.

Given the high cost, complexity, and uncertainty involved in executing this type of complex project, it is our assumption that a high level of construction knowledge or skill is needed to tackle the challenges in these projects. Accordingly, the contractors have considerable knowledge regarding construction work and pricing, which owners may not have. In addition, these projects may also experience many change orders and claims during the construction phase due to the complexity and uncertainty involved. Accordingly, we also assume the primary characteristics of this type of complex project are closely related to determining the value-added dimension of owners $\left(v a_{O}\right)$ and of contractors $\left(v a_{C}\right)$. The value-added dimension of owners $\left(v a_{O}\right)$ is the value generated when owners do not transfer their tacit knowledge. Therefore, it refers to the profits resulting from the lowest price and risk avoidance through low-bid procurement in conjunction with a lump sum contract. The value-added $\left(v a_{C}\right)$ dimension is the value generated when contractors do not transfer the knowledge related to the operational strategy and pricing. The value can be denoted as individual profits resulting from concealing design and engineering errors in the bidding phase of the projects in the DBB delivery method and making change orders in the construction phase.

\subsubsection{Low Bid Procurement with a Lump-Sum Contract in the DBB Project Delivery Method}

In projects using low bid procurement, owners expect perfect plans and specifications from contractors for keeping construction costs within the agreed amount or minimizing cost increases [31]. In addition, a lump-sum contract method requires contractors to 
complete the project for a fixed price and take the risk of cost overrun [32]. Accordingly, when the project applies low-bid procurement in conjunction with a lump-sum contract, the owners do not share their tacit knowledge about available budget. It enables the owners to have value-added $\left(v a_{O}\right)$ knowledge led by the lowest price and risk avoidance. Given the hypothetical case, projects are large and complex with high risk and difficulty, and the impact of the $v a_{O}$ will be very substantial.

On the other hand, if contractors do not share their tacit knowledge about design errors and omission during bidding phase, they can have value-added $\left(v a_{C}\right)$ knowledge about design errors and omissions and submit change orders after the award of contract. This situation is observed by several studies [33-35] illustrating that projects using low bid procurement have many change orders, claims, and disputes. The impact of $v a_{C}$ will also be very significant due to the size and complexity of the case projects.

Subsequently, we can define $v a_{O}$ and $v a_{C}=5$ (very high), which means the negativereverse impact $\left(n r i_{i}\right)=5$ because the value of $n r i_{i}$ is equivalent to the value of $v a_{i}$ according to Table 3. When contractors share their knowledge (e.g., potential design errors and omissions discovered during bidding), owners can leverage the knowledge to prevent unnecessary change orders, which gives the owners slightly high or very high leveragability $\left(L_{O}\right)$. In a DBB project, because owners do not share their tacit knowledge about budget, the contractors are not able to obtain knowledge leveragability $\left(L_{C}\right)$.

\subsubsection{Best Value Procurement with GMP or IPD Contracts}

In projects using best value procurement, owners expect to pay for higher bid price than projects using low bid procurement, aiming to acquire a higher qualified contractor who can deliver better construction quality and cost performance during the construction phase [36-38]. In addition, a GMP contract allows contractors to establish a maximum price within which the project should be completed [39]. The cost savings resulting from the project completion within the maximum price can be shared between the owner and the contractor on a mutually agreed upon ratio [39-41]. An IPD contract enables all the stakeholders, including architect, owner, and contractors, to be responsible for project costs by having them share risks and rewards from the project [42,43]. Accordingly, applying best value procurement with GMP or IPD contracts means the owners share their tacit knowledge about available budget, thus not having value-added $\left(v a_{O}\right)$ knowledge.

In contrast, in projects where contractors do not share their tacit knowledge, they can have value-added $\left(v a_{C}\right)$ knowledge by potentially submitting higher bid prices with overengineering or creating change orders for increasing contractors' individual profits. Considering the size and complexity of the case projects, the impact of $v a_{C}$ will be also very significant; thus, we can define $v a_{C}=5$ (very high). However, these opportunistic behaviors may lead to project failure, increasing project costs and causing project delays. This assumption is supported by the study of Marinelli and Antoniou [44] which demonstrated successful delivery of the best value project depends on high competition among competent contractors, improving the cost efficiency of technical solutions, discouraging future scope changes, and establishing objectivity, fairness, and transparency in the process of contract award.

In addition, contractors benefit from slightly high or very high leveragability $\left(L_{C}\right)$; for example, in IPD projects, contractors can leverage the target budget knowledge shared by the owner to increase their profits through performance-based incentives and shared IPD contingency. Accordingly, we can define: $L_{C}=4$ (slightly high) or 5 (very high). In addition, if contractors share their tacit knowledge, owners can leverage the knowledge to obtain quality works at a reasonable cost with minimum waste and change orders, which gives the owners slightly high or very high leveragability $\left(L_{O}\right)$.

\subsubsection{Commonly Applied Values: Synergy and Basic Value}

We assume that collaboration, disputes, and claims have impacts due to the high risk and difficulty of a project type. Especially, collaboration can have many positive effects on 
the performance of the case project. According to Eriksson and Westerberg [45], when a construction project is challenging due to its size, complexity, and uncertainty, cooperative procurement procedures among the project stakeholders and the project performance have a highly positive relationship. Therefore, we can define $S=4$ (slightly high) or 5 (very high) in the case project, which is a large and complex project.

Finally, basic value $\left(r_{i}\right)$ is the fundamental, inherent value of knowledge itself. Accordingly, we assume the basic value of the knowledge from both stakeholders $\left(r_{i}\right)$ is very low because the knowledge in this setting has value only when the stakeholders interact with each other. Therefore, we can define: $r_{i}=1$ (very low). These values are commonly applied to all the decisions of owners and contractors.

\subsection{Four Potential Scenarios}

Given these numerical values for each dimension, we have developed four different scenarios:

(1) Scenario 1: $v a_{i}=5\left(n r i_{i}=5\right), r_{i}=1$, and $L_{i}=4$ when $S=4$ or 5

(2) Scenario 2: $v a_{i}=5\left(n r i_{i}=5\right), r_{i}=1$, and $L_{i}=5$ when $S=4$ or 5

(3) Scenario 3: $v a_{i}=5\left(n r i_{i}=5\right), r_{i}=1$, and $L_{O}=5>L_{C}=4$ when $S=4$ or 5

(4) Scenario 4: $v a_{i}=5\left(n r i_{i}=5\right), r_{i}=1$, and $L_{O}=4<L_{C}=5$ when $S=4$ or 5

5.2.1. Scenario 1: An Owner's and Contractor's Leveragability of Shared Knowledge $\left(L_{i}\right)$ Is Slightly High

In Scenario 1, the owner's and contractor's leveragability of shared knowledge $(L)$ is determined as slightly high $\left(L_{i}=4\right)$. In addition, the synergy $(S)$ is determined as either slightly high $(S=4)$, which is Scenario $1-1$, or very high $(S=5)$, which is Scenario 1-2. Table 6 indicates the payoff matrix of Scenario 1. The payoffs in the table are calculated with the functions provided in Table 4 . Figure 1 illustrates the Nash equilibrium points and Pareto frontier of the strategy pairs in Scenario 1. The Pareto frontier is a line consisting of Pareto optimal points.

Table 6. Payoff matrix of Scenario 1.

\begin{tabular}{cccccc}
\hline & \multirow{2}{*}{$\boldsymbol{r}_{\boldsymbol{i}}=\mathbf{1}, \boldsymbol{v} \boldsymbol{a}_{\boldsymbol{i}}=\mathbf{5}, \boldsymbol{n r i}_{\boldsymbol{i}}=\mathbf{5}$ and $\boldsymbol{L}_{\boldsymbol{i}}=\mathbf{4}$} & & \multicolumn{2}{c}{ Contractor } \\
\cline { 4 - 6 } Scenario 1-1 & $S=4$ & Owner & $\begin{array}{c}\mathrm{T} \\
\text { DNT }\end{array}$ & $\begin{array}{c}(5,5) \\
(11,-4)\end{array}$ & $\begin{array}{c}(-4,11) \\
*(6,6)\end{array}$ \\
\hline \multirow{2}{*}{ Scenario 1-2 } & $S=5$ & Owner & $\begin{array}{c}\text { T } \\
\text { DNT }\end{array}$ & $\begin{array}{c}(6,6) \\
(11,-4)\end{array}$ & $\begin{array}{c}(-4,11) \\
*(6,6)\end{array}$ \\
\hline
\end{tabular}

${ }^{*}$ Nash equilibrium.
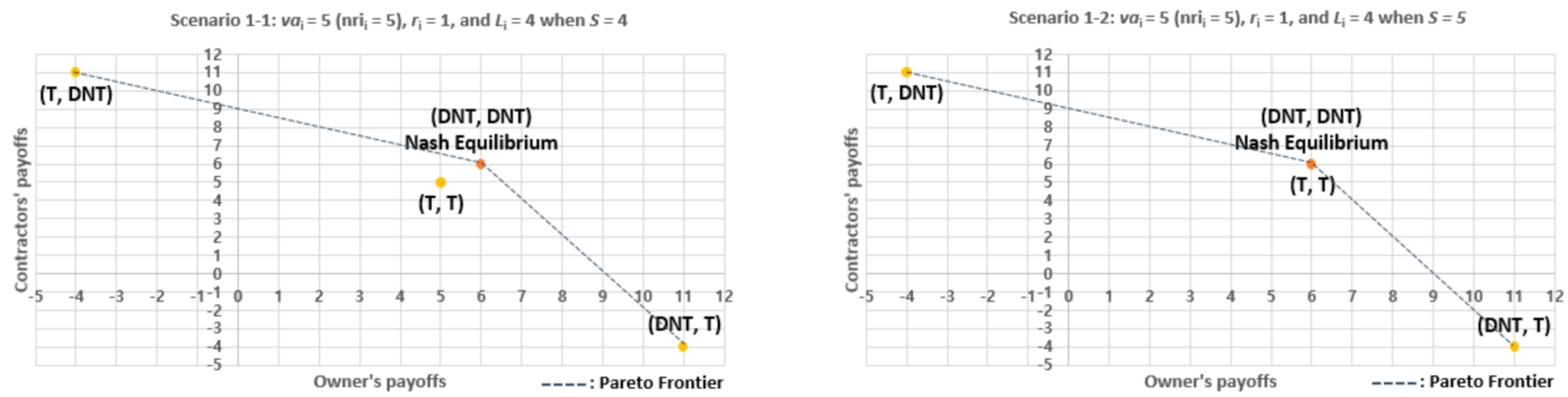

Figure 1. Nash equilibrium and Pareto frontier in Scenario 1.

In Scenario 1-1 and 1-2, the strategy pair (DNT, DNT) is in both Nash equilibrium and Pareto optimality, providing both stakeholders with the maximized payoffs in the 
most risk-safe state. This means that owners and contractors can maximize their payoffs in the most risk-safe state when they do not transfer their tacit knowledge to each other. Accordingly, when the owner's and contractor's leveragability of shared knowledge $(L)$ is estimated as slightly high $\left(L_{i}=4\right)$, which means the knowledge-receiving party can slightly increase its decision payoffs by exploiting the shared knowledge for its own benefit beyond the cooperation, it is the optimal decision for the owner to not transfer knowledge by choosing low bid procurement with a lump-sum contract. From the perspective of the contractor, it is the optimal decision that the contractor does not transfer knowledge by concealing design and engineering errors in the bidding phase of DBB and making change orders in the construction phase to make additional profit. However, Figure 1 also shows that the payoffs of $(\mathrm{T}, \mathrm{T})$ increase when $S$ is enhanced from slightly high $(S=4)$ to very high $(S=5)$. Subsequently, both $(T, T)$ and (DNT, DNT) are in Nash equilibrium and Pareto optimality in Scenario 1-2 where synergy is very high. This means that the owner and contractor are also able to obtain the maximized payoffs by sharing their tacit knowledge in a GMP or IPD contract when they trust each other in high synergistic collaboration. The result implies that the owner and the contractor in the GMP or IPD contract-based projects should be collaborative by being transparent in order to maximize their payoffs in the projects.

5.2.2. Scenario 2: An Owner's and Contractor's Leveragability of Shared Knowledge $\left(L_{i}\right)$ Is Very High

In Scenario 2, the owner's and contractor's leveragability of shared knowledge $(L)$ is determined as relatively higher than the $L$ in Scenario 1, which means $L_{i}$ is very high $\left(L_{i}=5\right)$. In addition, the synergy $(S)$ is determined as either slightly high $(S=4)$, which is Scenario 2-1, or very high $(S=5)$, which is Scenario 2-2. Table 7 indicates the payoff matrix of Scenario 2. The payoffs are calculated with the functions provided in Table 4. Figure 2 illustrates the Nash equilibrium points and Pareto frontier of the strategy pairs in Scenario 2.

Table 7. Payoff matrix of Scenario 2.

\begin{tabular}{|c|c|c|c|c|c|}
\hline \multirow{2}{*}{\multicolumn{4}{|c|}{$r_{i}=1, v a_{i}=5, n r i_{i}=5$ and $L_{i}=5$}} & \multicolumn{2}{|c|}{ Contractor } \\
\hline & & & & $\mathbf{T}$ & DNT \\
\hline Scenario 2-1 & $S=4$ & Owner & $\begin{array}{c}\text { T } \\
\text { DNT }\end{array}$ & $\begin{array}{c}(6,6) \\
(12,-4)\end{array}$ & $\begin{array}{c}(-4,12) \\
*(6,6)\end{array}$ \\
\hline Scenario 2-2 & $S=5$ & Owner & $\begin{array}{c}\text { T } \\
\text { DNT }\end{array}$ & $\begin{array}{c}(7,7) \\
(12,-4)\end{array}$ & $\begin{array}{c}(-4,12) \\
*(6,6)\end{array}$ \\
\hline
\end{tabular}

* Nash equilibrium.
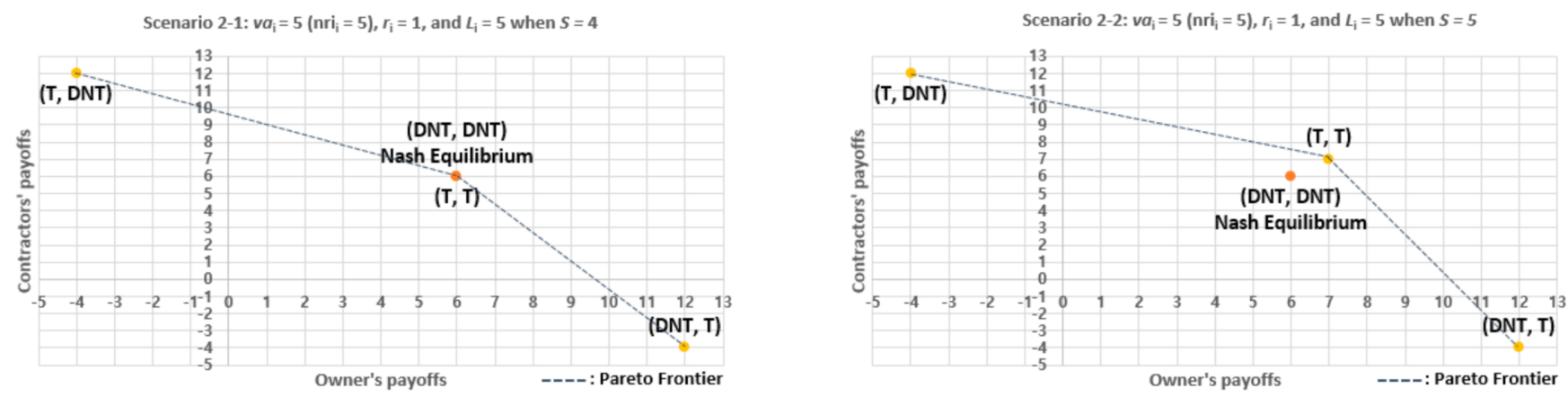

Figure 2. Nash equilibrium and Pareto frontier in Scenario 2.

In Scenario 2-1, (DNT, DNT) is in Nash equilibrium point and Pareto optimality, and $(\mathrm{T}, \mathrm{T})$ is in Pareto optimality. It means both decision pairs provide maximized payoffs to the stakeholders. However, it also implies that even though $(\mathrm{T}, \mathrm{T})$ can also provide maximized 
payoffs, the stakeholders may have a preference to go with (DNT, DNT) because it is in the Nash equilibrium state. In Scenario 2-2 in which $S$ is enhanced from slightly high $(S=4)$ to very high $(S=5)$, (DNT, DNT) is still in the Nash equilibrium point because the change in $S$ is not able to impact the owner's and contractor's decisions on Nash equilibrium. For example, when the contractor's decision is T or DNT, the owner will choose DNT because the owner's payoff from DNT is greater than the payoff from T. This decision process is identically applied to the contractor when the owner's decision is T or DNT. Accordingly, the Nash equilibrium point will be (DNT, DNT) in Scenario 2-2. However, the difference from Scenario 2-1 is that both stakeholders can obtain better payoffs by deviating from the Nash equilibrium point (DNT, DNT) to the Pareto optimal point $(\mathrm{T}, \mathrm{T})$. Thus, if the owner's and contractor's leveragability of shared knowledge $(L)$ is very high $\left(L_{i}=5\right)$, both stakeholders can obtain the higher payoffs by sharing their tacit knowledge in the best value procurement with GMP or IPD contracts in high synergistic collaboration $(S=5)$.

5.2.3. Scenario 3: An Owner's Leveragability of Shared Knowledge Is Higher than a Contractor's Leveragability of Shared Knowledge

In Scenario 3, the owner's leveragability of shared knowledge $\left(L_{O}\right)$ is relatively higher than the contractor's leveragability of shared knowledge $\left(L_{C}\right)$. In addition, the synergy $(S)$ is determined as either slightly high $(S=4)$, which is Scenario 3-1, or very high $(S=5)$, which is Scenario 3-2. Table 8 indicates the payoff matrix of Scenario 3. The payoffs are calculated with the functions provided in Table 4 . Figure 3 illustrates the Nash equilibrium points and Pareto frontier of the strategy pairs in Scenario 3.

Table 8. Payoff matrix of Scenario 3.

\begin{tabular}{|c|c|c|c|c|c|}
\hline \multirow{2}{*}{\multicolumn{4}{|c|}{$r_{i}=1, v a_{i}=5, n r i_{i}=5$ and $L_{O}=5>L_{C}=4$}} & \multicolumn{2}{|c|}{ Contractor } \\
\hline & & & & $\mathbf{T}$ & DNT \\
\hline Scenario 3-1 & $S=4$ & Owner & $\begin{array}{c}\text { T } \\
\text { DNT }\end{array}$ & $\begin{array}{c}(6,5) \\
(12,-4)\end{array}$ & $\begin{array}{l}(-4,11) \\
*(6,6)\end{array}$ \\
\hline Scenario 3-2 & $S=5$ & Owner & $\begin{array}{c}\text { T } \\
\text { DNT }\end{array}$ & $\begin{array}{c}(7,6) \\
(12,-4)\end{array}$ & $\begin{array}{l}(-4,11) \\
*(6,6)\end{array}$ \\
\hline
\end{tabular}

*Nash equilibrium.
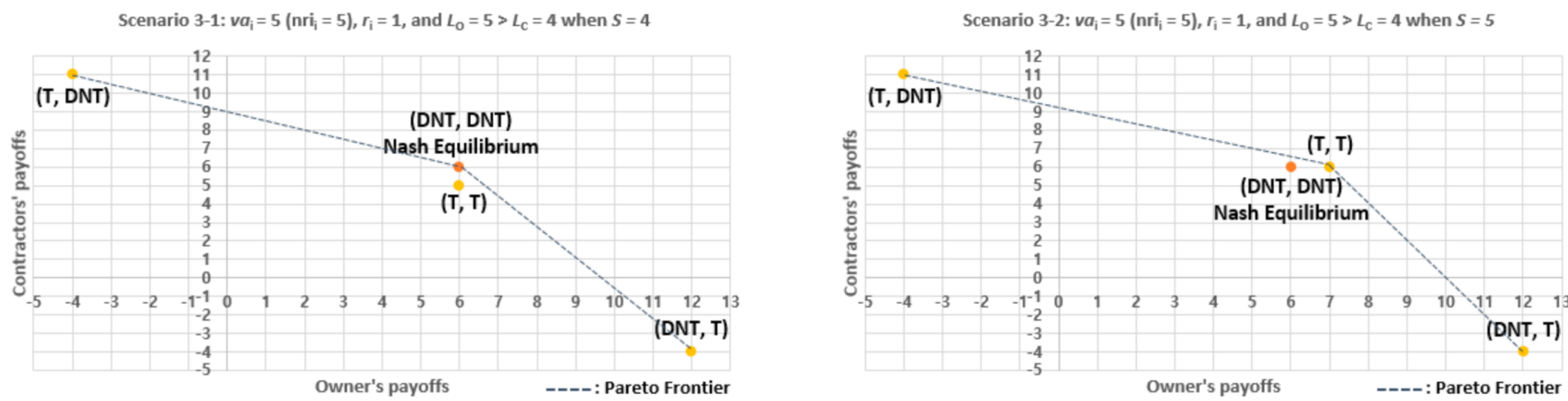

Figure 3. Nash equilibrium and Pareto frontier in Scenario 3.

As with Scenario 2, (DNT, DNT) is in the Nash equilibrium in both Scenario 3-1 and 3-2. However, unlike Scenario 2-1, $(T, T)$ is not in the Pareto optimality in Scenario 3-1, in which the synergy is slightly high $(S=4)$. Accordingly, in Scenario 3-1, both stakeholders do not deviate from the Nash equilibrium point (DNT, DNT) to the (T, T). However, in Scenario 3 -2, in which $S$ is enhanced from slightly high $(S=4)$ to very high $(S=5)$, owners can obtain better payoffs by deviating from the Nash equilibrium point (DNT, DNT) to the Pareto optimal point $(\mathrm{T}, \mathrm{T})$. In this setting, contractors' payoffs do not increase. Consequently, when $L_{O}$ is higher than $L_{C}$, the owner should persuade the contractor to become engaged in 
the project with full transparency in the best value procurement with GMP or IPD contracts so as to increase their payoffs. Incentives can be used to encourage contractors to engage in collaborative and transparent interactions with the owner, which can ultimately increase both stakeholders' payoffs.

5.2.4. Scenario 4: A Contractor's Leveragability of Shared Knowledge Is Higher than an Owner's Leveragability of Shared Knowledge

On the other hand, Scenario 4 , in which $L_{O}$ is slightly high and $L_{C}$ is very high, shows different results. Table 9 indicates the payoff matrix of Scenario 4 . The payoffs are calculated with the functions provided in Table 4 . Figure 4 illustrates the Nash equilibrium points and Pareto frontier of the strategy pairs in Scenario 4.

Table 9. Payoff matrix of Scenario 3.

\begin{tabular}{|c|c|c|c|c|c|}
\hline \multirow{2}{*}{\multicolumn{4}{|c|}{$r_{i}=1, v a_{i}=5, n r i_{i}=5$ and $L_{O}=4<L_{C}=5$}} & \multicolumn{2}{|c|}{ Contractors } \\
\hline & & & & $\mathrm{T}$ & DNT \\
\hline Scenario 4-1 & $S=4$ & Owner & $\begin{array}{c}\text { T } \\
\text { DNT }\end{array}$ & $\begin{array}{c}(5,6) \\
(11,-4)\end{array}$ & $\begin{array}{c}(-4,12) \\
*(6,6)\end{array}$ \\
\hline Scenario 4-2 & $S=5$ & Owner & $\begin{array}{c}\text { T } \\
\text { DNT }\end{array}$ & $\begin{array}{c}(6,7) \\
(11,-4)\end{array}$ & $\begin{array}{c}(-4,12) \\
*(6,6)\end{array}$ \\
\hline
\end{tabular}

* Nash equilibrium.
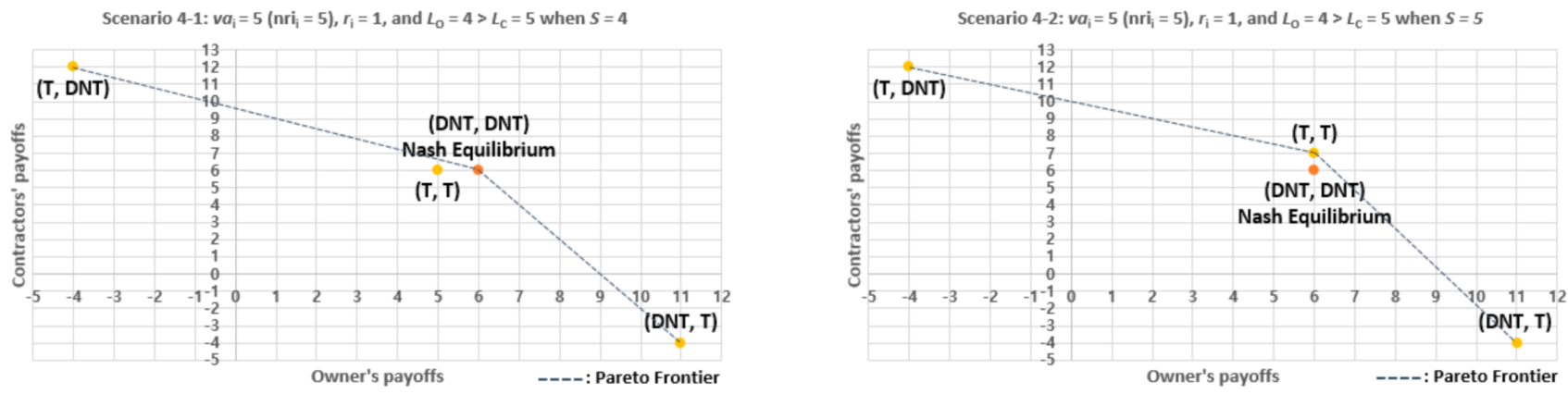

Figure 4. Nash equilibrium and Pareto frontier in Scenario 4.

Figure 4 illustrates that (DNT, DNT) is in the Nash equilibrium in Scenario 4-1 and 4-2. The Nash equilibrium (DNT, DNT) is also in the Pareto optimality in Scenario 4-1, in which the synergy is slightly high $(S=4)$. However, in Scenario 4-2 in which $S$ is enhanced from slightly high $(S=4)$ to very high $(S=5)$, the Nash equilibrium point (DNT, DNT) is not in the Pareto optimality. In this setting, contractors can obtain better payoffs by deviating from the Nash equilibrium point (DNT, DNT) to the Pareto optimal point (T, T). In contrast, the owner's payoffs do not increase when the decision pair deviate from (DNT, DNT) to (T, $\mathrm{T})$. Consequently, when $L_{C}$ is higher than $L_{O}$, the contractor should persuade the owner to transfer their tacit knowledge in the best value procurement with GMP or IPD contracts so as to increase their payoffs.

\section{Discussion}

The analysis of the scenarios demonstrates that in complex construction projects involving high risk, the strategy pair (DNT, DNT) provides owners and contractors with a Nash equilibrium state in which they can have the optimal payoffs regardless of an opposing stakeholder's decision in deciding whether or not to transfer their tacit knowledge. The (DNT, DNT) also generates the maximized payoffs for both stakeholders when the synergy between stakeholders is slightly high $(S=4)$ compared to the scenarios in which $S$ is very high $(S=5)$. When the synergy is relatively low, owners may choose not to share their tacit knowledge by using low-bid procurement with a lump-sum contract, and 
contractors may not share their tacit knowledge by not disclosing design and engineering errors that they discover at the time of biding in DBB project cases.

The analysis of scenarios also revealed that the owner and contractors should deviate from the (DNT, DNT) strategy pair to the $(\mathrm{T}, \mathrm{T})$ strategy pair in order to increase their payoffs when $L_{O}$ and $L_{C}$ are very high, and $S$ is enhanced from slightly high to very high. Because the Nash equilibrium (DNT, DNT) lies beneath the Pareto frontier, the strategy pair $(\mathrm{T}, \mathrm{T})$ can provide better payoffs to both stakeholders than the strategy pair (DNT, DNT). In this case, stakeholders are better off to trust each other and share their tacit knowledge in order to obtain better payoffs, which means owners would leverage best value procurement with GMP or IPD contracts, and contractors become engaged more collaboratively in the project with full transparency.

The analysis also demonstrates that if the $L$ of one stakeholder is estimated as higher than the $L$ of an opposing stakeholder, the stakeholder whose $L$ is larger than the opposing stakeholder's $L$ can generate better payoffs without decreasing the opposing stakeholder's payoff by deviating from the Nash equilibrium state (DNT, DNT) to the strategy pair (T, T). Thus, in this case, the stakeholder whose $L$ is larger than the opposing stakeholder's $L$, would seek cooperation and knowledge sharing from the opposing stakeholder in best value procurement with GMP or IPD contracts to enhance the synergy and thus increase the payoffs. The increased payoffs may be shared to persuade the opposing stakeholders. The optimal decisions for each scenario in large and complex projects are summarized in Table 10 .

Table 10. Optimal decisions for each scenario in large and complex projects.

\begin{tabular}{|c|c|c|c|c|}
\hline Scenarios & $\begin{array}{c}\text { Scenario 1: } \\
L_{i}=4\end{array}$ & $\begin{array}{l}\text { Scenario 2: } \\
\qquad L_{i}=5\end{array}$ & $\begin{array}{c}\text { Scenario 3: } \\
L_{O}>L_{C}\end{array}$ & $\begin{array}{c}\text { Scenario 4: } \\
L_{C}>L_{O}\end{array}$ \\
\hline Synergy is slightly high $(S=4)$ & (DNT, DNT) & $\begin{array}{c}(\mathrm{T}, \mathrm{T}) \text { or } \\
(\mathrm{DNT}, \mathrm{DNT})\end{array}$ & (DNT, DNT) & (DNT, DNT) \\
\hline Synergy is very high $(S=5)$ & $\begin{array}{c}(\mathrm{T}, \mathrm{T}) \text { or } \\
(\mathrm{DNT}, \mathrm{DNT})\end{array}$ & $(\mathrm{T}, \mathrm{T})$ & $\begin{array}{l}(\mathrm{T}, \mathrm{T}) \text {-better payoffs } \\
\text { for owners }\end{array}$ & $\begin{array}{l}(\mathrm{T}, \mathrm{T}) \text { - better payoffs } \\
\text { for contractors }\end{array}$ \\
\hline
\end{tabular}

Please note that the developed scenarios and their associated insights and conclusions are limited by the definition of the dimensions used to quantify the value of tacit knowledge and project characteristic-based assumptions. Changes in the definition, the assumptions, or the values measured may significantly affect the conclusions or insights generated from the framework. Accordingly, when the framework is applied to real construction projects, the owners and contractors should confirm whether the definitions of the dimensions for quantifying tacit knowledge values capture all aspects of the tacit knowledge associated with their project. In addition, when they measure the value of tacit knowledge in their project, they should consider the project characteristics that can impact the measurement. Nevertheless, the proposed framework can serve as a guideline that enables owners and contractors to measure the values of tacit knowledge and analyze the results of sharing or not sharing tacit knowledge in their own projects.

\section{Conclusions}

Sharing tacit knowledge among construction stakeholders heavily impacts construction project performance. Accordingly, many studies have defined tacit knowledge in construction projects and investigated how to capture it and how to facilitate the transfer of it across the construction supply chain. Despite the valuable findings from previous studies, the studies were limited to tacit knowledge sharing at the construction phase that can be used to improve construction productivity or efficiency. In addition, most of these studies have focused on tacit knowledge management and sharing in project teams involving individuals, such as architects, engineers, and contractors. 
However, tacit knowledge sharing between owners and contractors is also critical for successful construction projects. Owners have tacit knowledge on the maximum budget that can be financed for construction projects. Contractors have tacit knowledge related to construction operational strategies and pricing. Sharing this knowledge is closely associated with the owners' decisions on procurement and contract types and contractors' decisions on their level of collaboration or transparency. Collaboration and knowledge sharing could lead to successful projects and higher profits for both stakeholders if procurement and incentives are set appropriately. Nevertheless, the definitions of owners' and contractors' tacit knowledge, the impact of sharing the knowledge on both stakeholders, and how the decision on whether to share the knowledge can be made, have not yet been studied.

This research proposes a quantitative framework to examine the dynamics of tacit knowledge sharing between owners and contractors in construction projects. The framework defines the tacit knowledge of owners and contractors and quantifies its value using the five dimensions: basic value, value-added associated with monopolistic knowledge, synergy, leveragability, and negative-reverse impact. The framework subsequently computes the payoff matrix of sharing tacit knowledge and analyzes the payoffs based on game-theoretical approaches using the Nash equilibrium and Pareto optimality. The Nash equilibrium offers the most risk-safe decision where a stakeholder can generate the optimal payoff regardless of the decision adopted by the opposing stakeholder; however, this state of equilibrium does not always maximize the payoffs for both stakeholders. Accordingly, the proposed framework also involves the examination of the Pareto optimality to generate maximized payoffs, enabling stakeholders to determine when to deviate from the Nash equilibrium state to achieve optimal payoffs. Hence, the proposed framework assists owners in identifying the optimal procurement and contract methods for achieving excellent project quality at a reasonable cost, given their assessment of project complexity, knowledge sharing leveragability, and synergy with contractors. Further, it helps contractors to determine when being collaborative and committed to knowledge sharing is most advantageous to them.

Additionally, this research validates the effectiveness of the proposed framework by a series of simulations using hypothetical scenarios of a mega construction project. The simulations illustrate the process of how the framework identifies the best decisions of owners and contractors in determining procurement and contract methods, as well as being collaborative in the projects. It also demonstrates that when owners' and contractors' knowledge leveragability $(L)$ is very high and synergy $(S)$ is enhanced as a result of knowledge sharing in mega construction projects, the Nash equilibrium state lies beneath the Pareto frontier. This means that sharing tacit knowledge transparently about budget by choosing the best value procurement with GMP or IPD contracts can promote collaboration and provide better payoffs to both stakeholders than not sharing the knowledge by choosing design-bid-build method using a low-bid procurement in conjunction with a fixed-price contract.

This research contributes to the body of knowledge by proposing a theoretical framework that enables both owners and contractors to understand the economics of collaboration in the context of complex projects. Through the framework the owners would identify the optimal procurement and contract methods for complex projects where enhanced collaboration is needed and understand how that would incentivize and trigger contractors' collaborative behavior. The framework also enables contractors to determine the economic payoffs from their collaborative actions in a project-specific context.

Despite these valuable contributions, this study has some limitations. First, we limited the scope of an owner's tacit knowledge to the financial knowledge that directly impacts decisions pertaining to procurement and contract methods. Thus, the authors recommend that future research investigate other types of tacit knowledge and examine the impact of them on the collaboration between owners and contractors. Second, the proposed framework is implemented in the theoretical case scenarios limited to large and complex projects with high risks. Future research could examine other scenarios of construction 
projects, which are not complex, and compare the results with the complex projects. This analysis will deepen the understanding of the relationship between project complexity and tacit knowledge transfer. In addition, the scenarios in the example section were developed for a given procurement and contract type, and did not include other alternatives, such as Design-Build or CM@Risk delivery methods and a Cost-Plus contract. Accordingly, this study recommends future research address the potential of other types of delivery methods and contracts in affecting tacit knowledge sharing dynamics. This paper will serve as a foundation for these future studies.

\begin{abstract}
Author Contributions: Conceptualization, J.H.Y. and P.P.-B.; methodology, J.H.Y. and P.P.-B.; formal analysis, J.H.Y.; investigation, J.H.Y.; writing-original draft preparation, J.H.Y. with direction and supervision, P.P.-B.; writing-review and editing, P.P.-B.; visualization, J.H.Y.; supervision, P.P.-B.; project administration, P.P.-B. All authors have read and agreed to the published version of the manuscript.
\end{abstract}

Funding: This research received no external funding.

Data Availability Statement: All data, models, and code generated or used during the study appear in the submitted article.

Conflicts of Interest: The authors declare no conflict of interest.

\title{
References
}

1. Pathirage, C.P.; Amaratunga, D.G.; Haigh, R.P. The role of tacit knowledge in the construction industry: Towards a definition. In Proceedings of the CIB W89 International Conference on Building Education and Research (BEAR), Heritance Kandalama, Sri Lanka, 11-15 February 2008.

2. Zhang, L.; He, J. Critical Factors Affecting Tacit-Knowledge Sharing within the Integrated Project Team. J. Manag. Eng. 2016, 32, 04015045. [CrossRef]

3. Woo, J.-H.; Clayton, M.J.; Johnson, R.E.; Flores, B.E.; Ellis, C. Dynamic Knowledge Map: Reusing experts' tacit knowledge in the AEC industry. Autom. Constr. 2004, 13, 203-207. [CrossRef]

4. Addis, M. Tacit and explicit knowledge in construction management. Constr. Manag. Econ. 2016, 34, 439-445. [CrossRef]

5. Pathirage, C.P.; Amaratunga, D.G.; Haigh, R.P. Tacit knowledge and organisational performance: Construction industry perspective. J. Knowl. Manag. 2007, 11, 115-126. [CrossRef]

6. Nesan, J. Factors Influencing Tacit Knowledge in Construction. Constr. Econ. Build. 2005, 5, 48-57. [CrossRef]

7. Hwang, S. Organizational Issues Affecting Tacit Knowledge Sharing in Construction Organizations. In Proceedings of the Construction Research Congress 2014: Construction in a Global Network, Atlanta, GA, USA, 19-21 May 2014.

8. Chen, L.; Mohamed, S. The strategic importance of tacit knowledge management activities in construction. Constr. Innov. 2010, 10, 138-163. [CrossRef]

9. Zhang, L.; He, J.; Zhou, S. Sharing Tacit Knowledge for Integrated Project Team Flexibility: Case Study of Integrated Project Delivery. J. Constr. Eng. Manag. 2013, 139, 795-804. [CrossRef]

10. ASCE. Quality in the Constructed Project: A Guide for Owners, Designers, and Constructors; American Society of Civil Engineers: New York, NY, USA, 2012.

11. Shan, Y.; Li, Z. Evolutionary game analysis of knowledge-sharing mechanism of construction supply chain towards construction industrialization. J. Eng. Manag 2015, 29, 5319.

12. Egbu, C.O.; Robinson, H.S. Construction as a Knowledge-Based Industry. Knowl. Manag. Constr. 2005, 4, 31-49.

13. Bakar, A.H.A. Effect of knowledge management on growth performance in construction industry. Manag. Decis. 2016, 54, 735-749.

14. Green, S. Learning across Business Sectors: Knowledge Sharing between Aerospace and Construction; The University of Reading: Berkshire, UK, 2004.

15. Tahir, M.B.; Khan, K.I.A.; Nasir, A.R. Tacit knowledge sharing in construction: A system dynamics approach. Asian J. Civ. Eng. 2021, 22, 605-625. [CrossRef]

16. Saini, M.; Arif, M.; Kulonda, D.J. Challenges to transferring and sharing of tacit knowledge within a construction supply chain. Constr. Innov. 2019, 19, 15-33. [CrossRef]

17. Kivrak, S.; Arslan, G. Conceptual framework for capturing tacit knowledge in construction projects. In eWork and eBusiness in Architecture, Engineering and Construction; CRC Press: Boca Raton, FL, USA, 2020; pp. 271-276.

18. Negara, K.; Suryo, E.; Wijatmiko, I. Tacit Knowledge Acquisition and Codification in Construction Industry: Evidence from Indonesia. In Proceedings of the International Conference on Innovation and Technology (ICIT 2021), 2021; Atlantis Press: Dordrecht, Amman, Jordan, 14-15 July 2021; Atlantis Press: Dordrecht, The Netherlands, 2021. Available online: https:/ / scholar.google.com/scholar?q=Tacit+Knowledge+Acquisition+and+Codification+in+Construction+Industry: +Evidence+from+Indonesia.\&hl=en\&as_sdt=0\&as_vis=1\&oi=scholar (accessed on 3 January 2022). 
19. Jung, W.; Ballard, G.; Kim, Y.-W.; Han, S.H. Understanding of target value design for integrated project delivery with the context of game theory. In Proceedings of the Construction Research Congress 2012: Construction Challenges in a Flat World, Wet Lafayette, IN, USA, 21-23 May 2012.

20. Loebecke, C.; Van Fenema, P.C.; Powell, P. Co-opetition and knowledge transfer. ACM Sigmis Database Adv. Inf. Syst. 1999, 30, 14-25. [CrossRef]

21. Myerson, R.B. Game Theory; Harvard University Press: Cambridge, MA, USA, 2013.

22. Raweewan, M.; Ferrell, W. Information sharing in supply chain collaboration. Comput. Ind. Eng. 2018, 126, 269-281. [CrossRef]

23. Fudenberg, D.; Tirole, J. Game Theory; MIT Press: Cambridge, MA, USA, 1991.

24. Pure Strategy Matrix from Games and Nash Equilibria. Available online: https://ocw.mit.edu/courses/economics/14-11insights-from-game-theory-into-social-behavior-fall-2013/study-materials/MIT14_11F13_Pure_strategy.pdf (accessed on 11 November 2020).

25. Chinchuluun, A. Pareto Optimality, Game Theory and Equilibria; Springer: Berlin/Heidelberg, Germany, 2008.

26. Wasonga, T.A.; Murphy, J.F. Learning from tacit knowledge: The impact of the internship. Int. J. Educ. Manag. 2006, 20, 153-163. [CrossRef]

27. Kothari, A.R.; Bickford, J.J.; Edwards, N.; Dobbins, M.J.; Meyer, M. Uncovering Tacit Knowledge: A Pilot Study to Broaden the Concept of Knowledge in Knowledge Translation. BMC Health Serv. Res. 2011, 11, 198. [CrossRef]

28. Fiori, C.; Kovaka, M. Defining Megaprojects: Learning from Construction at the Edge of Experience. In Proceedings of the Construction Research Congress 2005: Broadening Perspectives, San Diego, CA, USA, 5-7 April 2005.

29. Hu, Y.; Chan, A.P.C.; Le, Y.; Jin, R.-Z. From Construction Megaproject Management to Complex Project Management: Bibliographic Analysis. J. Manag. Eng. 2015, 31, 04014052. [CrossRef]

30. Remington, K.; Pollack, J. Tools for Complex Projects; Routledge: Oxford, UK, 2016.

31. Gransberg, D.D.; Ellicott, M.A. Best Value Contracting: Breaking the Low-Bid Paradigm. In Proceedings of the 40th Annual Meeting of AACE International, Vancouver, BC, Canada, 23-26 June 1996.

32. Chen, Q.; Xia, B.; Jin, Z.; Wu, P.; Hu, Y. Choosing Appropriate Contract Methods for Design-Build Projects. J. Manag. Eng. 2016, 32, 04015029. [CrossRef]

33. El Wardani, M.A.; Messner, J.I.; Horman, M.J. Comparing Procurement Methods for Design-Build Projects. J. Constr. Eng. Manag. 2006, 132, 230-238. [CrossRef]

34. Pesämaa, O.; Eriksson, P.E.; Hair, J.F. Validating a model of cooperative procurement in the construction industry. Int. J. Proj. Manag. 2009, 27, 552-559. [CrossRef]

35. Awwad, R.; Ammoury, M. Comparison of Various Competitive Bidding Methods from an Owner's Perspective. In Proceedings of the Construction Research Congress, 2018: Construction Information Technology, New Orleans, LA, USA, 2-4 April 2018.

36. Lines, B.C.; Kakarapalli, R.; Nguyen, P.H. Does Best Value Procurement Cost More than Low-Bid? A Total Project Cost Perspective. Int. J. Constr. Educ. Res. 2020, 18, 85-100. [CrossRef]

37. Dimitri, N. "Best value for money" in procurement. J. Public Procure 2013, 13, 149-175. [CrossRef]

38. Alleman, D.; Antoine, A.; Gransberg, D.; Molenaar, K.R. Comparison of Qualifications-Based Selection and Best-Value Procurement for Construction Manager-General Contractor Highway Construction. Transp. Res. Rec. J. Transp. Res. Board 2017, 2630, 59-67. [CrossRef]

39. Hashem, M.; Mehany, M.S. Claims and project performance between traditional and alternative project delivery methods. J. Leg. Aff. Disput. Resolut. Eng. Constr. 2018, 10, 04518017. [CrossRef]

40. Chan, D.W.M.; Chan, A.P.C.; Lam, P.T.I.; Wong, J.M.W. Empirical Study of the Risks and Difficulties in Implementing Guaranteed Maximum Price and Target Cost Contracts in Construction. J. Constr. Eng. Manag. 2010, 136, 495-507. [CrossRef]

41. Puddicombe, M.S. Why contracts: Evidence. J. Constr. Eng. Manag. 2009, 135, 675-682. [CrossRef]

42. Pishdad-Bozorgi, P. Case Studies on the Role of Integrated Project Delivery (IPD) Approach on the Establishment and Promotion of Trust. Int. J. Constr. Educ. Res. 2016, 13, 102-124. [CrossRef]

43. Pishdad-Bozorgi, P.; Beliveau, Y.J. Symbiotic Relationships between Integrated Project Delivery (IPD) and Trust. Int. J. Constr. Educ. Res. 2016, 12, 179-192. [CrossRef]

44. Marinelli, M.; Antoniou, F. Improving public works' value for money: A new procurement strategy. Int. J. Manag. Proj. Bus. 2019, 13, 85-102. [CrossRef]

45. Eriksson, P.E.; Westerberg, M. Effects of cooperative procurement procedures on construction project performance: A conceptual framework. Int. J. Proj. Manag. 2011, 29, 197-208. [CrossRef] 